\title{
MORPHOLOGICAL CHANGES IN GROWTH-PLATE CARTILAGE IN OSTEOGENESIS IMPERFECTA
}

\author{
C. SANGUinetTI, F. GRECO, L. DE PALMA, N. SPECCHIA, F. FAlCiglia
}

From the Catholic University of the Sacred Heart, Rome

\begin{abstract}
We obtained specimens of growth-plate cartilage from four patients with osteogenesis imperfecta. Light microscopy showed structural changes in the tissue and morphological changes in chondrocytes and matrix, particularly in the hypertrophic zone. There were changes in the process of calcification in the primary mineralisation zone of the cartilage.

We also found histochemical changes in the matrix glycosaminoglycans (GAGs) in the zones where physiological mineralisation was disturbed and where the trabeculae were interrupted and poorly mineralised. In addition to the known molecular defects in collagen, changes in GAGs and non-collagenous proteins are important factors in the pathogenesis of the disease.
\end{abstract}

The term osteogenesis imperfecta (OI) includes a mixed group of heritable connective tissue disorders causing bone fragility, blue sclerae and deafness (Baruffaldi and Sanguinetti 1957; Sillence, Senn and Danks 1979). This classic triad is not revealed in full in every patient (Sillence 1981), because of the genetic and the phenotypic heterogeneity of the disease. This accounts for the various eponyms and synonyms used since Ekmans's first description in 1788 (quoted by Sillence et al 1979). Most of the biochemical and pathomorphological changes in the numerous variants have been identified and there are many reports on the biochemical and structural changes involving collagen synthesis and osteoblastic activity (Ramser et al 1966; Haebara, Yamasaki and Kyogoku 1969; Falvo and Bullough 1973; Albright, Albright and Crelin 1975; Bullough, Davidson and Lorenzo 1981; Krieg et al 1981; Stöss 1983). Sillence's classification (Sillence et al 1979; Sillence 1981) seems to be the most complete, giving a thorough description of the hereditary mechanism of transmission obtained from the analysis of observed cases.

The aetiology is still unknown (Root 1984), but recent studies have explained some of the biochemical

C. Sanguinetti, MD. Professor

F. Greco. MD, Assistant Professor

L. de Palma, MD. Assistant Professor

N. Specchia, MD, Resident Assistant

F. Falciglia, MD, Resident Assistant

Department of Orthopaedics, Catholic University of the Sacred Heart.

School of Medicine, L.go Gemelli 8, 00168 Rome, Italy.

Correspondence should be sent to Dr F. Greco.

(C) 1990 British Editorial Society of Bone and Joint Surgery

$0301-620 X / 90 / 3073 \$ 2.00$

J Bone Joint Surg [ Br] 1990; 72-B : 475-9. aspects. Cultured fibroblasts from patients with OI, synthesise more type III than type I collagen: both type I and type III collagen are weaker and there are changes in the dimensions, structure and orientation of fibres (Penttinen et al 1975; Müller et al 1977; Sykes, Francis and Smith 1977; Brown 1981; Eyre 1981; Kirsch et al 1981; Sykes, Ogilvy and Wordsworth 1985). Structural changes have been described in the other matrix proteins with an increase in jaluronic acid and sulphatedglycosaminoglycans (GAGs) (Engfeldt and Hjerpe 1976; Cetta et al 1980; Hurst et al 1980; de Luca et al 1984), and related to the seriousness of the disease (Turakainen 1983).

Although the bony abnormalities of OI have been known for some time, changes in cartilage, especially those involving the growth plates have been little reported.

\section{MATERIALS AND METHODS}

Specimens of growth-plate cartilage were taken from three patients with OI, during the course of operations for traumatic tibial fractures, and from one seven-dayold patient who had died of lung failure. By Sillence's criteria, one patient had type 1, one had type 2 and two had type $3 \mathrm{OI}$.

All the specimens were obtained from the proximal or distal fibular epiphysis and fixed in $1 \%$ glutaraldehyde, $4 \%$ formaldehyde-buffered solution ( $\mathrm{pH} \mathrm{7.4)}$ ) for 48 hours at room temperature. One half of each specimen was decalcified, by stirring for 72 hours in $5 \%$ formic acid, thoroughly washed in tap water, dehydrated in graded alcohols, cleared in chloroform, embedded in paraffin, and cut into thin sections (5 to $6 \mu \mathrm{m}$ ). Staining was with 


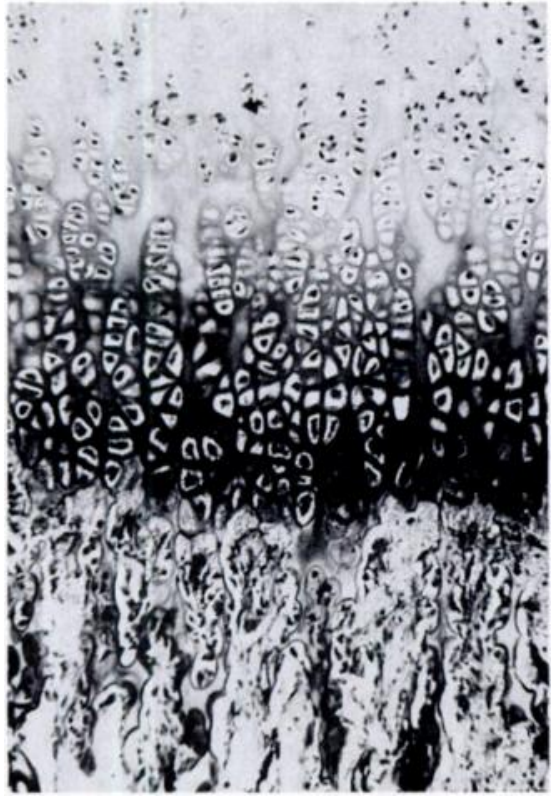

Fig. la

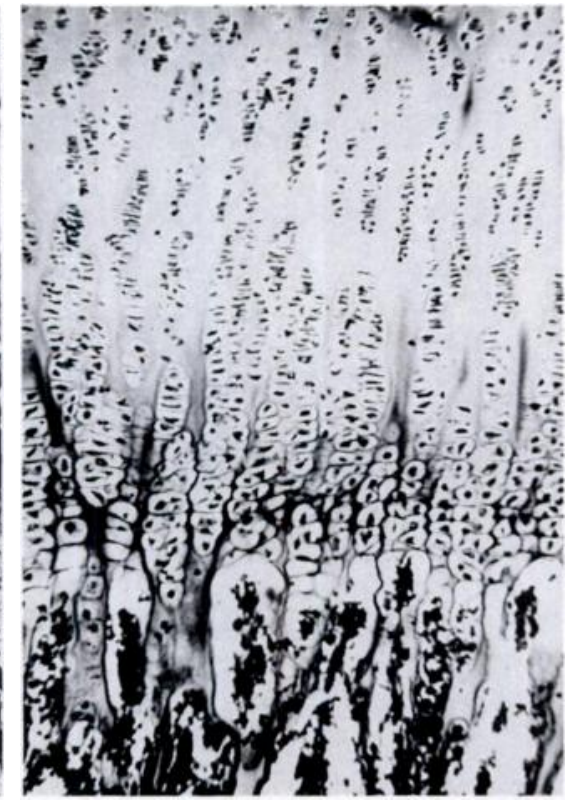

Normal growth-plate cartilage (a) and that from a patient with osteogenesis imperfecta (b). The hypertrophic cell layer shows a reduced PAS-staining, but persisting positive alcian blue staining (Alcian PAS $\times 20$ ). haematoxylin and eosin, Masson's trichrome, toluidine blue, alcian PAS and van Gieson stains. Alcian blue staining was performed at critical electrolyte concentration using different $\mathrm{MgCl}_{2}$ concentrations (Newton, Scott and Whiteman 1974). The sections were stained for 1 hour in $0.2 \%$ alcian blue in $0.025 \mathrm{M}$ sodium acetate buffer ( $\mathrm{pH} 5.8$ ) in $50 \% \mathrm{v} / \mathrm{v}$ ethanol, containing increasing concentrations of $\mathrm{MgCl}_{2}(0.05 \mathrm{M}$ to $1.2 \mathrm{M})$. Harris's haematoxylin was used for nuclear staining. The second half of each specimen was embedded undecalcified in methylmethacrylate, cut into thin sections and stained using the von Kossa method.

\section{RESULTS}

Light microscopy showed evidence of structural injury and of morphological changes in chondrocytes and matrix, particularly in the zone of the hypertrophic cells. Modification of the calcifying process was seen in the primary mineralisation zone of the cartilage. Our findings in agreement with Stöss (1985), showed morphological injuries in growth-plate cartilage in all four cases, although the damage was heterogeneous and related to the different types of Sillence's classification (Sillence 1981).

In type $2 \mathrm{OI}$, the quickly lethal form of the disease, there were paradoxically bland changes. In this type, there was a normal chondrocyte proliferation zone which merged into regularly structured cartilage columns. Persistently positive staining to alcian blue at high $\mathrm{MgCl}_{2}$ concentration in the deeper layer of the growthplate (Fig. 1) was, however, one pathological abnormality. In the primary mineralisation zone there were thin and scattered trabeculae, mainly of osteoid tissue and

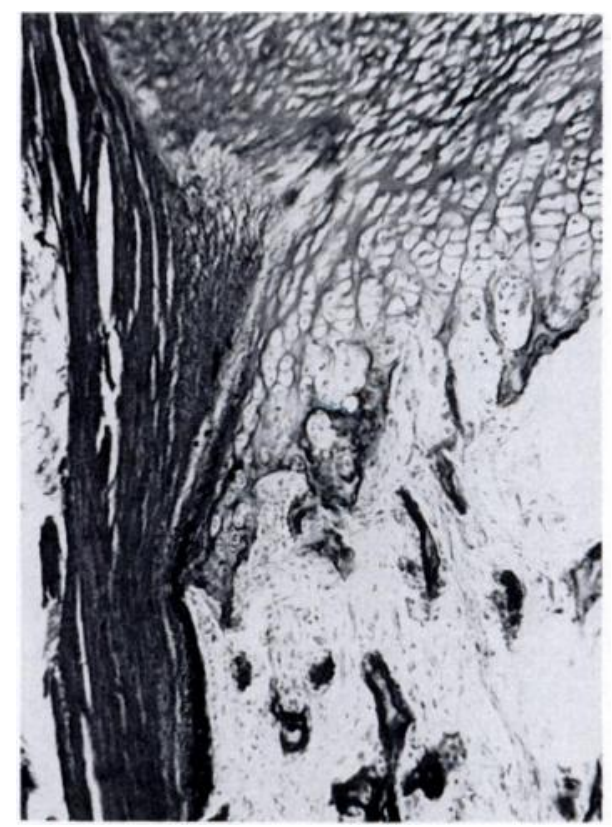

Fig. 2

Ossification groove of Ranvier from a patient with type $2 \mathrm{OI}$. There is excess of fibrous connective tissue and a reduced number of osteoblasts and chondroblasts (van Gieson × 20).

poorly mineralised. The perichondral or ossification groove of Ranvier also showed the same changes, and van Gieson's stain revealed much fibrous connective tissue and few osteoblasts and chondroblasts (Fig. 2).

In the other types of $O I$, histological changes were much more evident, and involved perichondrium, matrix and chondrocytes with different degrees of severity. The 
whole architecture of the growth-plate cartilage seemed to be disturbed because of the increased thickness of the hypertrophic zone. There was reduced cellularity and more stumpy, shorter columns in the proliferative zone. The cellular columns of the hypertrophic zone were irregular, poorly oriented, increased in width and variable in height. In some samples it was difficult to identify the longitudinal septa, and their matrix always showed a reduced affinity to PAS (Fig. 3).

Chondrocytes had a pyknotic nucleus, a swollen and vacuolated cytoplasm and showed reduction of intracellular alcian blue staining. The cells were abnormally grouped and seemed to be in a state of relative hyperplasia (Fig. 4). Moreover, the matrix of the hypertrophic zone of growth-plate cartilage showed a striking aniline stain affinity and was persistently positive to alcian blue at high $\mathrm{MgCl}_{2}$ concentrations. In the primary mineralisation zone, von Kossa staining of undecalcified samples showed scattered, non-homogeneous calcification with fragmented and distorted trabeculae (Fig. 5). Enchondral ossification was reduced and trichrome staining showed up the thinness, the low cellularity and the distortion of the newly-formed trabeculae (Fig. 6). Islets of nonmineralised residual cartilage remained in the cancellous
Figure 3-Growth-plate cartilage from a case of type $3 \mathrm{OI}$. Tissue architecture is disturbed by the increased thickness of the hypertrophic zone. There is reduced cellularity with stumpy and shorter columns in the proliferative zone Longitudinal septa are difficult to identify, and the matrix shows reduced PAS-affinity (Alcian PAS $\times 20$ ). Figure 4 - The cellular columns of the hypertrophic zone are irregular, badly orientated, increased in width and mixed in height. Chondrocytes are abnormally grouped and relatively hyperplastic. The matrix shows a persistent alcianophilia. (Alcian blue $0.5 \mathrm{M}$ $\left.\mathrm{MgCl}_{2} \times 40\right)$.

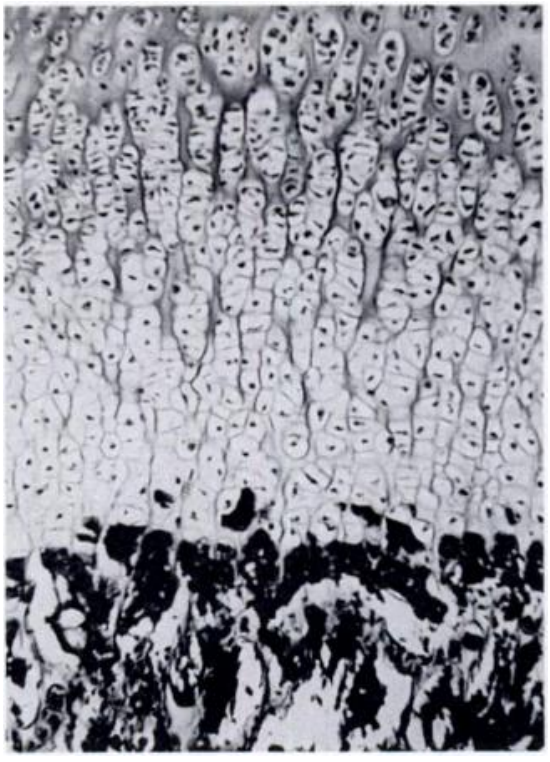

Fig. 3

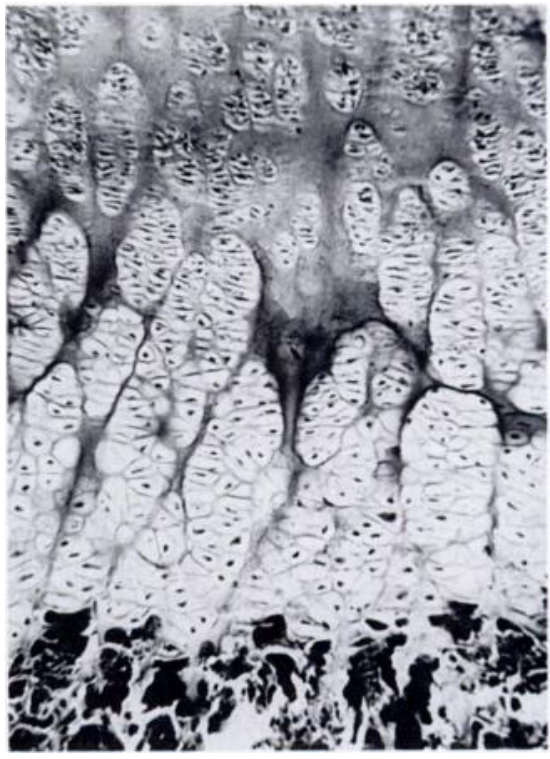

Fig. 4

Figure 5 - Growth-plate cartilage from type 1 OI. The primary mineralisation zone shows scattered, non-homogeneous calcification with fragmented and distorted trabeculae (von Kossa $\times 40$ ). Figure 6 - Growth-plate cartilage from type $3 \mathrm{OI}$. Enchondral ossification is redured The newlv-formed traheculae are 
bone of the proximal metaphysis. Metaphyseal cysts surrounded by fibrous tissue were often observed.

\section{DISCUSSION}

Our findings confirm that $\mathrm{OI}$ is a heterogeneous disease, not only by virtue of its multiple clinical and genetical aspects, so well described by Sillence, but also because of its different pathomorphological aspects (Weil 1981; Stöss 1983). As mentioned in our introduction previous histological and ultrastructural descriptions of OI have been concerned almost exclusively with bone (Stilling 1889; Ramser et al 1966; Haebara et al 1969; Falvo and Bullough 1973; Riley, Joswey and Brown 1973; Albright et al 1975; Bullough et al 1981; Stöss et al 1986), while pathological changes in growth-plate cartilage have been previously reported and discussed, to our knowledge, only by Bauer (1920) and Stöss (1985). The growth-plate changes we report confirm that $\mathrm{OI}$ is not a disease which affects only bone. Rather, these changes confirm the view of Bauer that $\mathrm{OI}$ is a systemic disease of the connective tissues.

Our observations agree with those of Stöss et al (1986), in making a clear distinction between the histological changes in type 2 and in those other forms of the disease. Even though type $2 \mathrm{OI}$ is rapidly lethal during the fetal period or just after birth, because of cardiac or lung failure, there are fewer and less severe pathological changes in growth cartilage. A possible explanation is that the metabolic injuries at the growth plate have not had time to develop into structural changes, though this does not seem to apply to the serious damage seen in bone and connective tissue.

Changes in enchondral ossification were always seen in the less serious types of OI. Cartilage matrix calcification seemed to be reduced, newly-formed trabeculae were scattered, thin and distorted, and islets of non-mineralised residual cartilage were often seen in the deeper layers of the metaphysis. Nevertheless we think that the cause of the osteogenetic defects in OI may be identified in pre-existent metabolic changes of the cartilaginous matrix. It is known that the relative proportions (Hascall and Sajdera 1969) and combinations of collagen, proteoglycans (PGs) and structural glycoproteins differ in the several zones of normal growth-plate cartilage (Quintarelli and Dellovo 1966). It is also known that alcian blue electively stains glycosaminoglycans (GAGs), which are the glycidic components of proteoglycans (Quintarelli and Dellovo 1965). Moreover, even if the critical salt-concentration theory developed by Scott and Dorling (1965) does not always hold true, it is the case that alcian blue at high $\mathrm{MgCl}_{2}$ concentration electively stains only those GAGs with the highest molecular weight and sulphated radicals. The normal extracellular matrix of growth-plate cartilage shows a high affinity to alcian blue at low $\mathrm{MgCl}_{2}$ concentrations, but at $0.5 \mathrm{M} \mathrm{MgCl}_{2}$ the alcianophilia of the extraterri- torial matrix of the proliferative and hypertrophic zones and of the intercolumnar longitudinal septa is weakest. These areas become alcian blue negative at 0.6 to $0.7 \mathrm{M} \mathrm{MgCl}_{2}$. The alcianophilia of the territorial matrix of the columns, of the resting zone, of transverse septa and of the cytoplasm of maturing and hypertrophic chondrocytes persists up to $1 \mathrm{M} \mathrm{MgCl}_{2}$ (Scott 1975). Moreover, it has been shown that the territorial matrix of resting and proliferative zones and of transverse septa hold the highest concentration of GAGs at high molecular weight (Quintarelli and Dellovo 1966). Therefore, the persistent alcianophilia at high $\mathrm{MgCl}_{2}$ concentrations, as shown by us, confirms the presence of PGs with high molecular weight in this zone. On the other hand, it has been previously reported that the PGs with high molecular weight can inhibit both the in vitro growth of hydroxyapatite crystals and the in vivo activity of alkaline phosphatase (Blumenthal et al 1979; Shepard and Mitchell 1985).

Alcian PAS stain shows the PAS-positivity of normal growth-plate matrix in the primary mineralisation zone, demonstrating the high structural glycoprotein content of this layer (Anderson 1962). Moreover, Bonucci (1971) reported that the deposition of calcium and hydroxyapatite crystals takes place only in the matrix vesicles of the primary mineralisation zone, forming needle-shaped aggregates which are highly PAS-positive after decalcification. The decrease in PAS-positivity of the matrix of the longitudinal septa of the hypertrophic layer in our OI samples proves the decrease of structural glycoproteins in the matrix.

Matrix vesicles are observed all along the longitudinal septa, but the calcification process starts only in the hypertrophic zone, where alkaline phosphatase activity begins to increase and the concentration of PGs with high molecular weight begins to decrease. OI cartilage samples stained by alcian blue at different $\mathrm{MgCl}_{2}$ concentrations show that high-molecular-weight PGs are also present in the hypertrophic layer. The persistence of these macromolecules inhibit alkaline phosphatase activity, and prevent the development of the normal calcification as shown by von Kossa staining. The reduced mineralisation and absence of change in the proliferative process may be the causes of hyperplasia in the hypertrophic layer. We also saw changes in the cartilage of the perichondral groove, but cannot state whether these have any direct consequences in the enchondral ossification.

There have been many recent reports on the aetiology and pathogenesis of $\mathrm{OI}$ and on its clinical heterogeneity, especially in relation to genetics and the structural changes in collagen (Riley et al 1973; Teitelbaum et al 1974; Penttinen et al 1975; Müller et al 1977; Sykes et al 1977, 1985; Eyre 1981; Kirsch et al 1981; Pontz, Kirsch and Müller 1981; Barsh, David and Byers 1982; Nicholls et al 1984), but there have been few reports of changes in PGs and other matrix proteins, even though their basic 
role in physiological matrix mineralisation is well known (Shepard and Mitchell 1985). Turakainen (1983), for example, measured an increase of jaluronic acid concentration and observed structural changes in GAGs in OI cultured fibroblasts, and was able to correlate the biochemical defect with the severity of the disease.

Our findings have allowed us to correlate the histochemical changes in matrix GAGs with the breakdown of physiological mineralisation which resulted in the formation of interrupted and scarcely mineralised trabeculae. Therefore, in addition to the known molecular defects in collagen, we feel that the role of GAG and non-collagenous protein changes in the development of OI should be emphasised. Further studies will be necessary to clarify the influence of matrix impairment in determining the different types of the disease.

No benefits in any form have been received or will be received from a commercial party related directly or indirectly to the subject of this article.

\section{REFERENCES}

Albright JP, Albright JA, Crelin ES. Osteogenesis imperfecta tarda : the morphology of rib biopsies. Clin Orthop 1975: 108:204-13.

Anderson AJ. Some studies on the relationship between sialic acid and the mucopolysaccharide-protein complexes in human cartilage. Biochem J 1962; 82:372-81

Barsh GS, David KE, Byers PH. Type I osteogenesis imperfecta: a non functional allele for pro alpha I (I) chains of type I procollagen. Pro Natl Acad Sci USA 1982; 79:3838-42.

Baruffaldi O, Sanguinetti C. Su alcuni casi di "Osteopsatirosi”. Clinica Ortopedica 1957: 9:387-405.

Bauer KH. Ueber Osteogenesis Imperfecta. Zugleich ein Beitrag zur frage einer allgemeinen Erkrankung sämtlicher Stützgewebe. Deutsche Ztschr Chir Leipz 1920: 154:166-213.

Blumenthal NC, Posner AS, Silverman LD, Rosenberg LC. Effect of proteoglycans on in vitro hydroxyapatite formation. Calcif Tissue Int 1979:27:75-82.

Bonucci E. The locus of initial calcification in cartilage and bone. Clin Orthop 1971: 78:108-39.

Brown DM. Biochemical abnormalities in osteogenesis imperfecta. Clin Orthop 1981: 159:75-9.

Bullough PG, Davidson DD, Lorenzo JC. The morbid anatomy of the skeleton in osteogenesis imperfecta. Clin Orthop 1981: 159:42-57.

Cetta G, Lenzi L, Balduini C, et al. Glycosaminoglycan alterations in osteogenesis imperfecta. Ital J Biochem 1980: 29:337-50.

De Luca G, Tira ME, Rindi S, et al. Proteoglycan modifications in cultured osteogenesis imperfecta skin fibroblasts. Ital $J$ Biochem $1984: 33: 403-12$.

Engfeldt B, Hjerpe A. Glycosaminoglycans of cartilage and bone tissue in two cases of osteogenesis imperfecta congenita. Acta Pathol Microbiol Immunol Scand [A] 1976: 84:488-94.

Eyre DR. Concepts in collagen biochemistry: evidence that collagenopathies underlie osteogenesis imperfecta. Clin Orthop 1981: 159:97-107.

Falvo K, Bullough PG. Osteogenesis imperfecta : a histometric analysis. J Bone Joint Surg [Am] 1973; 55-A :275-86.

Haebara HJ, Yamasaki Y, Kyogoku M. An autopsy case of osteogenesis imperfecta congenita: histochemical and electron microscopical studies. Acta Pathol Jpn 1969: 19:377-94.

Hascall VC, Sajdera SW. Proteinpolysaccharide complex from bovine nasal cartilage: the function of glycoprotein in the formation of aggregates. J Biol Chem 1969: $244: 2384-96$.

Hurst RE, Settine JM, Floyd WM, Lorincz AE. Glycosaminoglycan excretion in osteogenesis imperfecta. Clin Chim Acta 1980; $100: 307-11$.
Kirsch E, Krieg T, Remberger K, et al. Disorder of collagen metabolism in a patient with osteogenesis imperfecta (lethal type): increased degree of hydroxylation of lysine in collagen types I and III. Eur J Clin Invest $1981 ; 11: 39-47$.

Krieg T, Kirsch E, Matzen K, Müller PK. Osteogenesis imperfecta. Klin Wochenschr 1981; 59:91-3.

Müller PK, Raisch K, Matzen K, et al. Presence of type III collagen in bone from a patient with osteogenesis imperfecta. Eur J Pediatr 1977: 125:29-37.

Newton DJ, Scott JE, Whiteman P. The estimation of acid glycosaminoglycan-Alcian blue complexes eluted from electrophoretic strips. Anal Biochem 1974: 62:268-73.

Nicholls AC, Osse G, Schloon HG, et al. The clinical features of homozygous alfa 2(I) collagen deficient osteogenesis imperfecta. $J$ Med Genet 1984; $21: 257-62$.

Penttinen RP, Lichtenstein JR, Martin GR, et al. Abnormal collagen metabolism in cultured cells in osteogenesis imperfecta. Proc Natl Acad Sci USA 1975; 72:586-9.

Pontz BF, Kirsch E, Müller PK. Veränderungen des Kollagenstoffwechsel bei Patienten mit Osteogenesis imperfecta. Verh Dtsch Ges Pathol 1981; 65:487.

Quintarelli G, Dellovo MC. The chemical and histochemical properties of alcian blue: IV. Further studies on the methods for the identification of acid glycosaminoglycans. Histochemistry 1965: 5:196-209.

Quintarelli G, Dellovo MC. Age changes in the localization and distribution of glycosaminoglycans in human hyaline cartilage. Histochemistry 1966: 7:141-67.

Ramser JR, Villanueva AR, Pirok D, Frost HM. Tetracycline-based measurement of bone dynamics in 3 women with osteogenesis imperfecta. Clin Orthop 1966: 49:151-62.

Riley FC, Joswey J, Brown DM. Osteogenesis imperfecta : morphologic and biochemical studies of connective tissue. Pediatr Res 1973: 7:757-68.

Root L. The treatment of osteogenesis imperfecta. Orthop Clin North Am 1984; 15:775-90

Scott JE. Composition and structure of the pericellular environment: Physiological function and chemical composition of pericellular proteoglycan (an evolutionary view). Philos Trans $R$ Soc Lond (Biol) 1975; 271(912):135-42.

Scott JE, Dorling J. Differential staining of acid glycosaminoglycans (mucopolysaccharides) by alcian blue in salt solutions. Histochemie $1965 ; 5: 221-33$.

Shepard N, Mitchell N. Ultrastructural modifications of proteoglycans coincident with mineralization in local regions of rat growth plate. J Bone Joint Surg [ Am] 1985; 67-A :455-64.

Sillence D. Osteogenesis imperfecta: an expanding panorama of variants. Clin Orthop 1981: 159:11-25.

Sillence DO, Senn A, Danks DM. Genetic heterogeneity in osteogenesis imperfecta. J Med Genet 1979; 16:101-16.

Stilling H. Osteogenesis imperfecta. Ein beitrag zur Lehre von der sogenannten fötalen Rachitis. Virchow's Archir 1889; 115:357-70.

Stöss H. The pathomorphological inhomogeneity of osteogenesis imperfecta. Calcif Tissue Int 1983; 35 Suppl A 13:49.

Stöss H. Cartilaginous changes in osteogenesis imperfecta. In: Papadatos CJ. Bartsocas CS, eds. Endocrine genetics and genetics of growth. New York: Alan R. Liss, Inc, 1985:343-53.

Stöss H, Pontz BF, Pesch HJ, Ott R. Heterogeneity of osteogenesis imperfecta: biochemical and morphological findings in a case of type III according to Sillence. Eur J Pediatr 1986: 145:34-9.

Sykes B, Francis MJO, Smith R. Altered relation of two collagen types in osteogenesis imperfecta. N Engl J Med 1977: 296:1200)-3.

Sykes B, Ogilvie DJ, Wordsworth BP. Lethal osteogenesis imperfecta and a collagen gene delection: length polymorphism provides an alternative explanation. Hum Genet 1985: 70:35-7.

Teitelbaum SL, Kraft WJ, Land R, et al. Bone collagen aggregation abnormalities in osteogenesis imperfecta. Calcif Tissue Int 1974: 17:75-9.

Turakainen $\mathbf{H}$. Altered glycosaminoglycan production in cultured osteogenesis-imperfecta skin fibroblasts. Biochem $J$ 1983: 213: 171-8.

Weil UH. Osteogenesis imperfecta : historical background. Clin Orthop $1981: 159: 6-10$ 